\title{
Preferred incentives for improving Ugandan community health worker job satisfaction and retention
}

Frontline Health Project

Follow this and additional works at: https://knowledgecommons.popcouncil.org/departments_sbsr-rh

Part of the Community Health and Preventive Medicine Commons, Maternal and Child Health Commons, and the Public Health Education and Promotion Commons How does access to this work benefit you? Let us know!

\section{Recommended Citation}

Frontline Health Project. 2021. "Preferred incentives for improving Ugandan community health worker job satisfaction and retention," research brief. Washington, DC: Population Council. 


\section{PREFERRED INCENTIVES FOR IMPROVING UGANDAN COMMUNITY HEALTH WORKER JOB SATISFACTION AND RETENTION}

\section{BACKGROUND}

Uganda's community health worker ( $\mathrm{CHW}$ ) program is facing a high level of attrition, similar to global trends among many other $\mathrm{CHW}$ programs $(1,2)$.

In under-resourced health systems, $\mathrm{CHWs}$ play a critical role addressing significant health inequities by facilitating health care access within local, often rural, communities. CHWs provide support for public health campaigns, provide community health education and promotion, and initiate patient referrals to health care facilities, among other activities.

Uganda's CHWs, who comprise Village Health Teams (VHTs), provide maternal and newborn care and services in addition to general health education. VHTs also organize their communities for greater health service utilization (1). From 2001 to 2016, Uganda's CHW program trained over 179,000 VHTs throughout the country's 112 districts (2). Nongovernmental organizations (NGOs) deploy their own CHWs known locally as community health promoters (CHPs).

Heavy workloads, a lack of transportation, poor supervisory and logistical support, along with inadequate compensation and incentive structures inhibit motivation and contribute to high attrition among Uganda's VHTs (1,2). Given the critical role of $\mathrm{CHWs}$ in health promotion and service provision within communities, it is crucial to identify ways to enhance their support, including improving their working conditions with appropriate and realistic incentive packages (3).

This brief summarizes quantitative and qualitative findings from the Frontline Health project's discrete choice experiment (DCE) study in Uganda, implemented with collaborators from Johns Hopkins Bloomberg School of Public Health and Pathfinder International, and supported by Uganda's Ministry of Health.

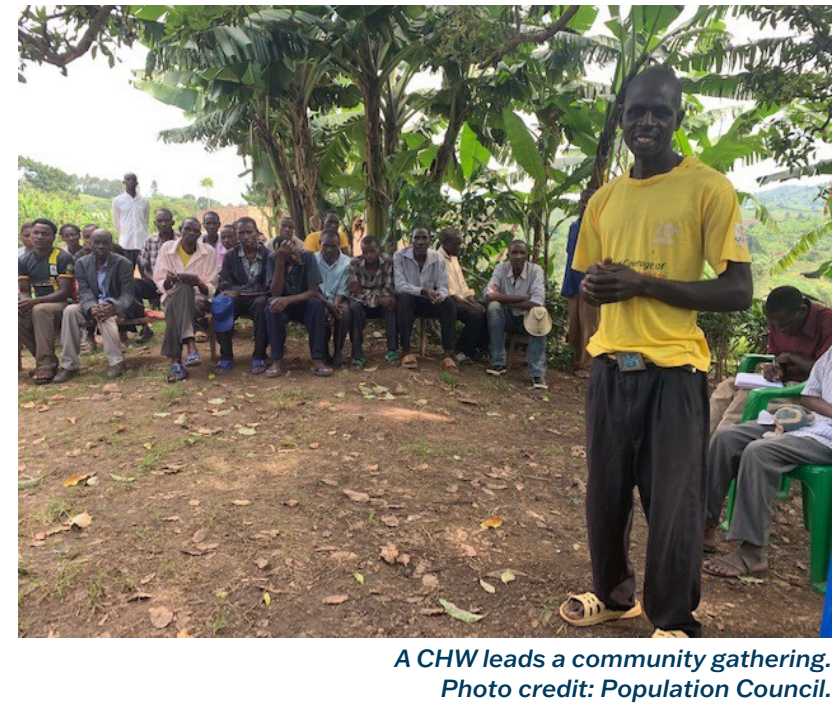

\section{KEY FINDINGS}

1. Uganda's CHWs prefer both monetary and non-monetary incentives to motivate them in their work.

2. Transportation was the most important factor for CHWs, followed by official identification, refresher trainings, and salary.

3. CHWs are willing to accept lower pay in exchange for other considerations: Governments and program managers should consider aspects other than remuneration when developing incentive packages.

This study was implemented in two phases in 2019. Phase 1 provided foundational understanding of CHW context and incentive preferences, which was built into the discrete choice experiment (DCE) implemented in Phase 2. The information presented in this brief is based on focus group discussions (FGDs) and in-depth interviews (IDIs) with a total of 114 participants including CHWs, CHW supervisors, along with district and national stakeholders (government and non-governmental), and a quantitative survey with $\mathrm{CHWs}(\mathrm{n}=399)$. Study phases 1 and 2 occurred in three and eight districts, respectively, to represent a range of geographic settings and working conditions (Table 1). More information about the study methodology is available in published manuscripts $(4,5)$. In this brief, CHWs refers to both VHTs and CHPs. 


\section{RESULTS}

CHWs received varied health training and provided a range of health services

Qualitatively, CHWs described receiving training, including refresher trainings, on a range of topics, including family planning, antenatal care, and HIV care and prevention.

"We go for home visits, we talk to them about antenatal [care], we also visit young babies age 0-5 years and we take them for immunization." - $\mathrm{CHW}$, Wakiso

In Phase 2 the mean age of CHWs interviewed was 44.5 years of age ( \pm 10.5 years). Fifty-nine percent of $\mathrm{CHWs}$ were female, and about $70 \%$ had at least a secondary education or higher. About $86 \%$ of $\mathrm{CHWs}$ reported walking to work, with the remaining $14 \%$ using some combination of bicycles, motorcycles, vehicles, and public transportation. About 95\% reported financial compensation for their work, with an average of USH 118,243 (\$30) provided per health event in which they participate (data not shown).

\section{Monetary compensation alone does not improve $\mathrm{CHW}$ motivation}

The results of this DCE (see Box 1) indicate that although $\mathrm{CHWs}$ would prefer jobs with higher salaries, they also desire jobs with reliable transportation, consistent training opportunities, official identification, reliable provision of job tools, less intense workloads, and recognition for their work. These survey results reveal that $\mathrm{CHWs}$ are willing to accept lower pay in exchange for consistent training and official identification.

Transportation: Reliable, affordable means of transportation are critical for $\mathrm{CHW}$ s to work efficiently, ease their commutes, and provide better access to the communities they serve. Currently, $\mathrm{CHWs}$ receive occasional transportation refunds for their travel needs, but amounts provided are, at times, negligible. CHWs often have to personally provide for their transportation to job sites, which can unduly burden them financially. In the DCE, bicycles were CHWs' preferred transportation option, followed by motorcycles.

"It will be better if we are given bicycles because there is a lot of work we do in the villages. [...] It becomes hard to walk on foot and be effective."-CHW, Mayuge

Some CHWs lack adequate transportation or means to attend job and skill trainings, when given the opportunity.

Refresher Trainings: CHWs prefer quarterly refresher trainings, both for the learning opportunities as well as the additional compensation that can accrue.
TABLE 1. METHODOLOGY FOR PHASE 1 AND 2

\begin{tabular}{|c|c|c|}
\hline \multicolumn{2}{|r|}{ Phase 1} & Phase 2 \\
\hline Where & $\begin{array}{l}\text { Lira, Mayuge, and } \\
\text { Wakiso Districts }\end{array}$ & $\begin{array}{l}\text { Lira, Mayuge, Wakiso, Ntungamo, } \\
\text { Kabale, Arua, Kabarole, Nakapirpirti } \\
\text { Districts }\end{array}$ \\
\hline Who & $\begin{array}{l}\text { CHWs, CHW } \\
\text { supervisors, } \\
\text { national-level } \\
\text { stakeholders }\end{array}$ & CHWs $(n=399)$ \\
\hline What & $\begin{array}{l}\text { Focus group } \\
\text { discussions (FGDs) } \\
\text { and in-depth } \\
\text { interviews (IDIs) }\end{array}$ & DCE (discrete choice experiment) \\
\hline Why & $\begin{array}{l}\text { To better } \\
\text { understand job } \\
\text { attributes (see } \\
\text { Table } 2 \text { ) that were } \\
\text { meaningful to } \\
\text { CHWs, and practical } \\
\text { from a policy-maker } \\
\text { perspective }\end{array}$ & $\begin{array}{l}\text { To experimentally test the job } \\
\text { attributes identified in Phase } \\
\text { using a DCE*, and identify which } \\
\text { attributes CHWs prefer. This is } \\
\text { done by presenting CHWs with two } \\
\text { hypothetical job scenarios with } \\
\text { differing combinations of attributes } \\
\text { and levels from Table } 2 \text {. }\end{array}$ \\
\hline
\end{tabular}

* A DCE is a quantitative technique which involves asking individuals to state their preferences in hypothetical scenarios. This can help researchers determine the preferred choices of respondents and their willingness for concessions. DCEs are based on Random Utility Theory, which estimates the benefit (i.e. utility) that an individual derives from Attribute A compared to Attribute B when given repeated choices (5). The influence of each attribute on the choice can be estimated mathematically to better understand preferred attributes.

Without adequate compensation, $\mathrm{CHWs}$ may be unable to participate in trainings.

"We need a refresher training on how to treat diarrhea, pneumonia, and anemia and how to take care of pregnant mothers when they deliver, how to sensitize them, they should keep training us." - $\mathrm{CHW}$, Lira

Currently, CHWs are not trained consistently. Trainings can support career advancement and provide CHWs' work with meaning and value.

Official Identification: CHWs preferred having methods of identification compared to none at all, with a strong preference for identification cards. Identification is important for $\mathrm{CHW}$ as it helps them in building stronger connections with their communities and health facilities. Identification can also help them assert their credibility:

"One of the problems I face while I am walking in the villages is I have no identification to show them that [I] am a [CHW], and we all look alike, [it] becomes a challenge because even when you tell them something, they look at you the way they want."-CHW, Mayuge 
Availability of Tools: $\mathrm{CHWs}$ would prefer mobile phones over paper-based job aids because mobile phones can support a wide range of activities, acting both as digital job aids and devices for collecting and storing data, in addition to improving CHWs' communication with their affiliated communities and work supervisors.

\section{"Mine was mentioning smartphone because [...] [it] can make our work easy and collect data easily. You know the world is advancing now, you cannot do anything with paper, you can send everything through a phone." - CHW, Lira}

Workload: CHWs manage both high workloads and inadequate compensation for their work. CHWs would prefer lighter workloads, such as four hours a day, two days a week. Heavy workloads can depress CHW motivation and result in lower job satisfaction, which is then exacerbated by their lack of monetary compensation and other incentives.

\section{"Our workload is not equivalent to the compensation, and yet we still do this work because we are volunteers." - $\mathrm{CHW}$, Wakiso}

Recognition: CHWs preferred opportunities for career progression and priority healthcare for them and their immediate family as means of recognition for their work. Recognition is critical for $\mathrm{CHWs}$ as it indicates external value and appreciation for their work. In addition to career progression and healthcare, CHWs also deeply appreciate and value their relationships with the community and healthcare facilities. The community themselves often refer to CHWs as 'musawo' - or doctor - which highlights the ownership and respect the community feels for them.

\section{BOX 1. PHASE 2 DCE RESULTS}

CHWs preferred higher monthly salaries, though salary was not the most important attribute. They preferred reliable transportation, such as a bicycle (Cl:1.06-2.67), motorcycle (Cl:1.27-2.34), or transport allowance (Cl:0.65-2.10). CHWs preferred formal identification including identity badges (Cl:0.72-2.49), branded uniforms (Cl:0.45-1.63), and protective branded gear (Cl:0.32-1.21) compared to no identification. They also preferred more regular refresher trainings, the use of mobile phones as job aids, and lesser workloads. The relative importance estimates suggest that transport was the most important attribute, followed by identification, refresher trainings, salary, workload, recognition, and availability of tools. CHWs were willing to accept a decrease in salary of USH 31,240 (\$8.50) for identity badges, and a decrease of USH 85,300 (\$23) for branded uniforms to no identification.
TABLE 2. ATTRIBUTES IDENTIFIED DURING PHASE 2

\begin{tabular}{|c|c|}
\hline Attribute & Levels \\
\hline Stipend & $\begin{array}{l}50,000 \text { USH }(\$ 13) / \text { month } \\
100,000 \text { USH }(\$ 27) / \text { month } \\
150,000 \text { USH }(\$ 41) / \text { month }\end{array}$ \\
\hline Refresher Trainings & $\begin{array}{l}\text { Quarterly } \\
\text { Bi-Annual } \\
\text { Annual } \\
\text { Every two years }\end{array}$ \\
\hline Identification & $\begin{array}{l}\text { Identity badges } \\
\text { Branded uniforms (e.g. t-shirts) } \\
\text { Branded protective gear (e.g. umbrella) }\end{array}$ \\
\hline Availability of tools & $\begin{array}{l}\text { Paper job-aids/manuals only } \\
\text { Work mobile phones with payment plans }\end{array}$ \\
\hline Transportation & $\begin{array}{l}\text { Bicycle } \\
\text { Transportation allowance } \\
\text { Motorcycle }\end{array}$ \\
\hline Recognition & $\begin{array}{l}\text { Membership in VHT club/association } \\
\text { Low-interest credit for starting business }\end{array}$ \\
\hline Workload & $\begin{array}{l}4 \text { hours a day/ } 2 \text { days a week } \\
8 \text { hours a day / } 2 \text { days a week } \\
4 \text { hours a day / } 4 \text { days a week }\end{array}$ \\
\hline
\end{tabular}

\section{CONCLUSION AND RECOMMENDATIONS}

\section{CHWs require both monetary and non-monetary support for optimal performance}

Investing in $\mathrm{CHWs}$ is critical, along with understanding their needs in addition to the specific contexts and factors of their work. Improving CHWs' working conditions can properly motivate them and improve their performance. This study identifies practical potential incentive preferences determined by $\mathrm{CHWs}$ themselves that can provide not merely necessary remuneration, but non-monetary support and public recognition than can enhance their work and the results they can achieve for public health and wellness.

CHWs in Uganda are willing to accept lower pay in exchange for reliable transportation to their job sites, consistent training opportunities, official identification, reliable provision of job tools, less intense workloads, and tangible recognition for their work.

Evidence from this study is relevant for key community health stakeholders in Uganda working to strengthen its $\mathrm{CHW}$ programs and policies. Key stakeholders in Uganda may consider the importance of supporting $\mathrm{CHWs}$ with a reasonable salary or other form of monetary compensation, in addition to exploring expanded non-monetary incentives.

We recommend a carefully considered combination of monetary and non-monetary incentives provided by $\mathrm{CHW}$ programs for improving $\mathrm{CHW}$ motivation, satisfaction, retention, and ultimately, performance. 


\section{BOX 2. STUDY STRENGTHS AND LIMITATIONS}

The formative work in Phase 1 provided a stronger understanding of stakeholder perspectives, which helped identify job characteristics that are the most policy-relevant and actionable, while also being meaningful to CHWs. However, as with other DCEs, a key limitation of this study is that the job attributes presented to CHWs are still hypothetical and may not be systematically understood by all the CHWs. Additionally, CHW preferences may be influenced by their organizational affiliations and prior experiences. A potential follow-up for this study is to practically test the results by implementing the preferred job attributes and assessing how it influences the motivation and retention of $\mathrm{CHWs}$.

\section{RESEARCHER CONTACTS}

Smisha Agarwal

Assistant Professor, Department of International Health Johns Hopkins Bloomberg School of Public Health

sagarw23@jhu.edu

\section{Richard Kintu}

Palladium

richard.kintu@uhss.co.ug

Timothy Abuya

Population Council, Kenya

tabuya@popcouncil.org

Suggested citation: Frontline Health Project and Johns Hopkins Bloomberg School of Public Health. 2021. Preferred Incentives for Improving Ugandan Community Health Worker Satisfaction and Retention. Washington, D.C.: Population Council.

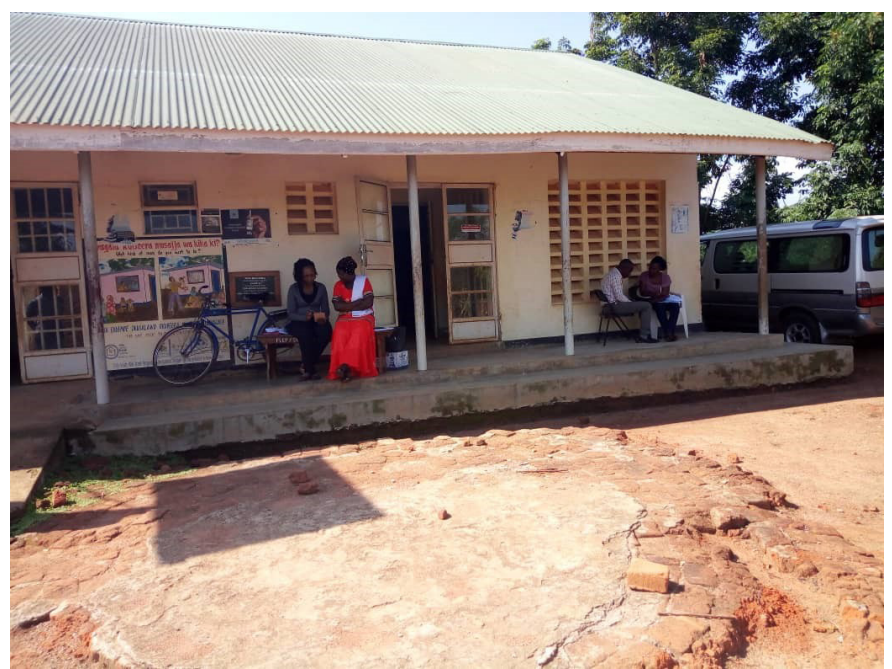

A CHW is interviewed outside of a health centre. Photo credit: Population Council.

\section{REFERENCES}

1. Republic of Uganda Ministry of Health, United Nations, IDEAL Development Consults Limited, Pathfinder International. National Village Health Teams (VHT) Assessment in Uganda. 2015; (March): 339.

2. Mays DC, O'Neil EJ, Mworozi EA, Lough BJ, Tabb ZJ, Whitlock AE, et al. Supporting and retaining Village Health Teams: An assessment of a community health worker program in two Ugandan districts. Int J Equity Health. 2017;16(1):1-10.

3. World Health Organization, WHO, World Health Organization. WHO Guideline on health policy and system support to optimize community health worker programmes. Geneva, Switzerland; 2018.

4. Agarwal S, Abuya T, Kintu R, Mwanga D, Obadha M, Pandya S, CE Warren. Understanding Community Health Worker Incentive Preferences in Uganda Using Discrete Choice Experiments. Journal of Global Health: accepted.

5. Agarwal S, Anaba U, Abuya T, Kintu R, Casseus A, Hossain S, et al. Understanding incentive preferences of community health workers using discrete choice experiments: A multicountry protocol for Kenya, Uganda, Bangladesh and Haiti. BMJ Open. 2019;9(12):1-8. 